\title{
Association of Vitamin D With Prostate Carcinoma: A Single Institutional Observational Study
}

\author{
Surya Kant Choubey ${ }^{\mathrm{a}}$, Gotam Pipara ${ }^{\mathrm{a}, \mathrm{b}}$, \\ Saurabh Mittal
}

\begin{abstract}
Background: Recent studies highlight a role for vitamin D (VD) in the growth and differentiation of various cell types. The biologically active form of vitamin D3 is 1,25-dihydroxyvitamin D3. Most cells of the body including prostate cells have vitamin D receptor (VDR) and VD metabolizing enzymes, and can respond to 1,25-VD. Literature supports multipronged effects of $1,25-\mathrm{VD}$ in the prevention of prostate carcinoma development and progression. However, the relationship between prostate carcinoma and VD is still not entirely understood. There are no studies conducted on the association of VD and prostate carcinoma among the Asian population and our study is the first of its kind in literature and hence the need for the same.
\end{abstract}

Methods: All men more than 50 years of age who presented to our hospital between July 2015 and July 2017 with lower urinary tract symptom (LUTS), and had a suspicious digital rectal examination (DRE) and hypoechoic areas on transrectal ultrasound (TRUS), were considered for the study. Those patients whose biopsies came as malignancy were taken as study subjects and patients with a negative biopsy were taken as controls. VD and serum prostatic-specific antigen (PSA) was done for all patients undergoing biopsy.

Results: Eighty-six men underwent prostate biopsy for suspicious DRE with hypoechoic areas on TRUS. Out of the 86 men, 66 men had a positive histopathology, suggestive of adenocarcinoma of the prostate gland (group A), and the remaining 20 men (group B) had a negative biopsy. All patients diagnosed with malignancy had severe VD deficiency and was found to be statistically significant.

Conclusion: VD deficiency is a risk factor for development of prostate carcinoma and there is a strong correlation between them. Further trials are however required to study the effect of VD supplementation on the natural course of the disease.

Keywords: Vitamin D deficiency; Carcinoma prostate; Calcitriol

Manuscript submitted September 6, 2017, accepted October 12, 2017

aDepartment of Urology and Renal Transplant, St John's Medical College and Hospital, Bangalore, India

${ }^{b}$ Corresponding Author: Gotam Pipara, Department of Urology and Renal Transplant, St John's Medical College and Hospital, Bangalore, Karnataka, India. Email: gotampipara@gmail.com

doi: https://doi.org/10.14740/wjnu317w

\section{Introduction}

Vitamin D (VD) is best known for its actions in regulating calcium levels and bone remodeling [1] (reviewed in Brown et al, 1999), but recent studies highlight a role for VD in the growth and differentiation of various cell types [2, 3]. VD may be obtained from the dietary sources; however, it is majorly synthesized in the skin by the action of sunrays. The biologically active form of vitamin D3 is 1,25-dihydroxyvitamin D3 (1,25-VD). Cholecalciferol from the skin and ergocalciferol from dietary sources are biologically inactive. The first hydroxylation takes place in the liver by 25 -hydroxylase and forms calcidiol (25 hydroxy VD), and calcidiol is then transported by alpha globulin to the proximal tubules of the kidneys where $1 \alpha$-hydroxylation takes place forming 1,25 VD. 1,25-VD is also called calcitriol. The actions of 1,25-VD are mediated by the vitamin $\mathrm{D}$ receptor (VDR), a ligand-activated transcription factor. Upon activation by $1,25-\mathrm{VD}$, VDR forms a heterodimer with the retinoid $\mathrm{X}$ receptor, and binds to vitamin D response elements (VDREs) in the promoters of VD-responsive genes [4]. Most cells of the body including prostate cells have VDR and VD metabolizing enzymes, and can respond to 1,25-VD. Literature supports multipronged effects of $1,25-\mathrm{VD}$ in the prevention of prostate carcinoma progression by induction of detoxifying enzymes [5], cell cycle arrest [6], and apoptosis [7], as well as inhibition of prostate carcinoma cell invasion [8] and angiogenesis [9]. Calcitriol demonstrates antiproliferative effects through the increase of cyclin-dependent kinase (CDK) inhibitors p21 and p27 expression, and the decrease in CDK activity, leading directly to G0/G1 cell cycle arrest [10-12]. Calcitriol also induces apoptosis, mainly through the stimulation of pro-apoptotic gene BAX and suppression of anti-apoptotic genes, such as BCL2 [13]. Malignant cells might acquire a more mature phenotype in response to calcitriol, suggestive of pro-differentiating effect via regulation of beta catenin, PI3K and JUNN-terminal kinase signaling pathway. Calcitriol inhibits tumor invasion and metastasis via matrix metalloproteinases (MMPs) [14]. Many epidemiological studies examining the VD and cancer association have been conducted; however, the relationship between prostate carcinoma and VD still remains not entirely understood [15]. There are no studies conducted on the association of VD and prostate carcinoma among the Asian population and our study is the first of its kind in literature and hence the need for the same. 
Table 1. Comparison of Patients in Group A and Group B in Terms of Symptoms, Lab Values and Peak Flow

\begin{tabular}{|c|c|c|c|c|c|c|c|}
\hline & \multicolumn{2}{|c|}{ Group A } & \multicolumn{2}{|c|}{ Group B } & \multicolumn{2}{|c|}{ Group A vs. group B } & \multirow{2}{*}{$\begin{array}{c}\text { Group A vs. group B } \\
\text { Mann-Whitney U-test (P values) }\end{array}$} \\
\hline & Mean \pm SD & Median & Mean \pm SD & Median & t value & P value & \\
\hline Age (years) & $70.4 \pm 8.0$ & 70.5 & $67.4 \pm 5.2$ & 68 & 1.58 & $0.12, \mathrm{NS}$ & - \\
\hline USG & $54.8 \pm 17.1$ & 56 & $51.6 \pm 14.2$ & 30 & 0.85 & $0.40, \mathrm{NS}$ & - \\
\hline PSA & $50.4 \pm 43.5$ & 34 & $6.5 \pm 3.0$ & 2.4 & 8.15 & $0.00 * *$ & $0.00 * *$ \\
\hline
\end{tabular}

Unpaired $t$-test. ${ }^{*} \mathrm{P}<0.05, \mathrm{~S} ;{ }^{* *} \mathrm{P}<0.001, \mathrm{HS} ; \mathrm{P}>0.05, \mathrm{NS}$.

\section{Materials and Methods}

All men more than 50 years who presented to the Department of Urology or were referred here for evaluation of lower urinary tract symptoms (LUTSs) at St John's Medical College and Hospital, Bangalore, Karnataka, India between July 2015 and July 2017 were considered for the study. All men more than 50 years presenting with bothersome LUTSs underwent a routine urological evaluation in the form of detailed history taking, physical examination including genitalia and a per rectal examination. Any nodule, hard gland on consistency, asymmetry on examination, fixed/puckered mucosa over prostate gland were all considered suspicious for malignancy. A urine routine microscopy, culture, ultrasound of the kidney, ureter, bladder (KUB), and uroflowmetry test were ordered. Uroflowmetry was not done for patients who were already on catheter. In patients, in whom the digital rectal examination (DRE) was suspicious, transrectal ultrasound (TRUS), VD assay and serum prostatic-specific antigen (PSA) were ordered. All men who had a suspicious DRE and hypoechoic areas on TRUS, irrespective of the PSA values were subjected to TRUS-guided six-core biopsy from each lobe. Patients whose biopsies were reported as positive for malignancy, prostate adenocarcinoma, were taken as study subjects and those whose biopsies came negative, suggestive of benign prostatic hyperplasia, were taken as controls. All patients had their VD level assessed at our hospital laboratory only, St John's, Bangalore to avoid differences in lab values. VD was measured by radioimmunoassay method. For the purpose of our analysis, VD insufficiency was defined as $20-30 \mathrm{ng} / \mathrm{dL}$ and $\mathrm{VD}<20 \mathrm{ng} / \mathrm{dL}$ as VD deficiency. Values of more than $30 \mathrm{ng} /$ $\mathrm{dL}$ were considered as normal. Serum PSA of 0 - $4 \mathrm{ng} / \mathrm{mL}$ was considered normal.

\section{Results}

Of all the men who presented to us during that period, 86 men underwent prostate biopsy for suspicious DRE with hypoechoic areas on TRUS. Out of the 86 men who underwent biopsy, 66 men had a positive histopathology suggestive of adenocarcinoma of the prostate gland (group A), and the remaining 20 men (group B) had a negative biopsy. The average age of men undergoing biopsy was 70.4 years in group A and 67.4 years in group B. The average size of the prostate gland of subjects in group A was approximately $54.8 \mathrm{~g}$ while that in group B was $51.6 \mathrm{~g}$. Both the results were statistically non-significant (Table 1). Subjects in group A had LUTSs for a mean of 8.8 months while those in group B for 13.4 months. This was statistically significant $(\mathrm{P}=0.017)$ which can most probably be explained by malignant nature of these glands that would have a comparatively rapid growth compared to their benign counterparts. The average PSA value among subjects in group A (Fig. 1) was $50.4 \mathrm{ng} / \mathrm{mL}$ while that in group $\mathrm{B}$ was $6.5(\mathrm{P} \leq$ 0.001 , highly significant). Mean VD level in group A was 10.1 $\mathrm{ng} / \mathrm{dL}$ while that in group B was $23.2 \mathrm{ng} / \mathrm{dL}(\mathrm{P} \leq 0.001$, highly significant). The average peak flow of the subjects in group $\mathrm{A}$ was $11.9 \mathrm{~mL} / \mathrm{s}$ while of those in group B was $13.5 \mathrm{~mL} / \mathrm{s}$ (not significant).

\section{Discussion}

Prostate carcinoma accounts for the most frequently diagnosed malignancy in men and the second leading cause of men's death from cancer worldwide [16]. In addition to its well-known role in regulating calcium homeostasis in the body via its actions in the kidney, bone, intestine, and parathyroid glands, VD also exhibits anti-tumorigenic properties. This knowledge has led to epidemiologic studies investigating the association between VD deficiency and prostate carcinoma. Accordingly, Schwartz and Hulka [17] were the first to propose that low levels of VD increase the risk of prostate carcinoma. Most studies of 1,25VD actions in prostate carcinoma have utilized human prostate carcinoma cell lines. The most widely studied cell lines are the LNCaP, PC-3, and DU145 cells. Of these, only the LNCaP cells express androgen receptor (AR) and are androgen-dependent (i.e., they do not grow in castrated hosts) in vivo [18]. Prostate carcinoma cells express receptors for 1,25-VD and some cell lines are growth inhibited when treated with 1,25VD [18]. The mechanism of action of these growth inhibitory effects of 1,25(OH)2D3 in LNCaP cells involves G1 accumulation, induction of quiescence, and an increase in apoptosis of the cancer cells. However, none of the studies have clearly demarcated the association between prostate carcinoma and VD. The meta-analysis of 26,769 cases conducted by Huncharek did not reveal a clear relationship between VD intake and pros- 


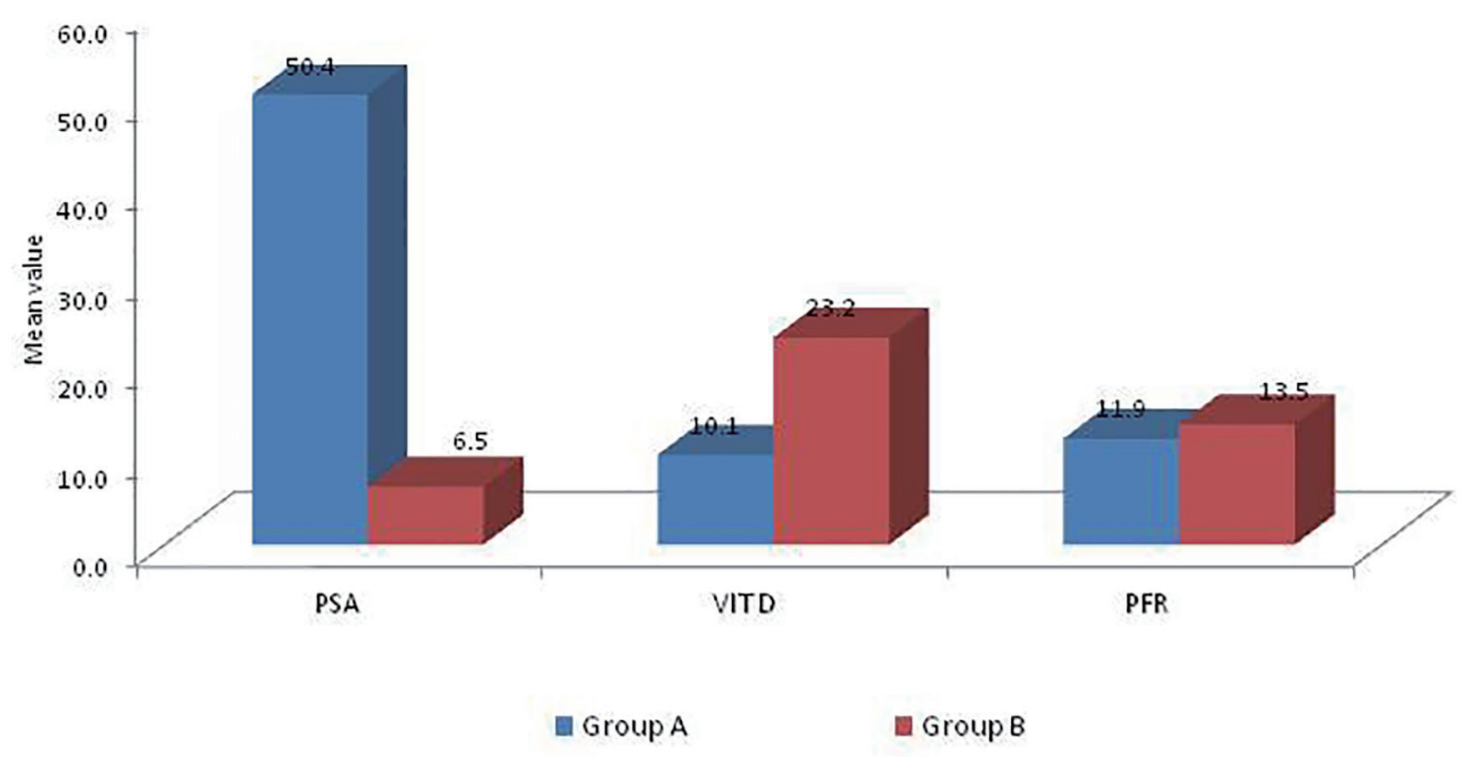

Figure 1. PSA, VD and peak flow level in two groups.

tate carcinoma risk [19]. However, the well-designed PCPT trial proved that circulating VD levels have a protective role on prostate carcinoma. Furthermore, the protective role of VD was related more with high-grade than with low-grade prostate carcinoma. Hence to hypothesize, VD inhibits the development of clinically significant, but not clinically insignificant, prostate carcinoma [20]. On the contrary, studies provided by $\mathrm{Xu}$ et al revealed a significant $17 \%$ elevation in risk of prostate carcinoma for individuals with higher level of VD [21]. No such studies have been conducted in the Asian population and our study is the first of its kind in the Asian population. In our study, we found that there was a significant correlation between VD deficiency and prostate carcinoma, the mean VD was 10.1 in group A (patients having prostate carcinoma) and 23.2 in group B (patients having benign prostatic hyperplasia). This probably indicates that men having VD deficiency have a greater risk of developing prostate carcinoma and perhaps VD supplementation in elderly patients may prove beneficial in slowing down prostatic growth and decreasing the risk of carcinoma.

In another study conducted to study the association between VD and PSA levels among black men, it was found that there was no effect on PSA levels, free or total with VD supplementation in men without a cancer diagnosis [22]. However, no correlation was made between patients who had cancer and VD deficiency. Our study clearly delineates that there is a strong correlation between VD deficiency and occurrence of prostate carcinoma.

\section{Conclusion}

VD deficiency is a risk factor for development of prostate carcinoma and there is a strong correlation between them. Further trials are however required to study the effect of VD supple- mentation on the natural course of the disease.

\section{Grant Support}

None.

\section{Funding Sources}

None.

\section{Conflict of Interest}

None.

\section{References}

1. Schenk JM, Till CA, Tangen CM, Goodman PJ, Song X, Torkko KC, Kristal AR, et al. Serum 25-hydroxyvitamin $\mathrm{D}$ concentrations and risk of prostate cancer: results from the Prostate Cancer Prevention Trial. Cancer Epidemiol Biomarkers Prev. 2014;23(8):1484-1493.

2. Kristal AR, Till C, Song X, Tangen CM, Goodman PJ, Neuhauser ML, Schenk JM, et al. Plasma vitamin D and prostate cancer risk: results from the Selenium and Vitamin E Cancer Prevention Trial. Cancer Epidemiol Biomarkers Prev. 2014;23(8):1494-1504.

3. Nyame YA, Murphy AB, Bowen DK, Jordan G, Batai K, Dixon M, Hollowell CM, et al. Associations between serum vitamin $\mathrm{D}$ and adverse pathology in men undergoing radical prostatectomy. J Clin Oncol. 2016;34(12):13451349. 
4. Kliewer SA, Umesono K, Noonan DJ, Heyman RA, Evans RM. Convergence of 9-cis retinoic acid and peroxisome proliferator signalling pathways through heterodimer formation of their receptors. Nature. 1992;358(6389):771774.

5. Bao BY, Ting HJ, Hsu JW, Lee YF. Protective role of 1 alpha, 25-dihydroxyvitamin D3 against oxidative stress in nonmalignant human prostate epithelial cells. Int J Cancer. 2008;122(12):2699-2706.

6. Bao BY, Hu YC, Ting HJ, Lee YF. Androgen signaling is required for the vitamin D-mediated growth inhibition in human prostate cancer cells. Oncogene. 2004;23(19):3350-3360.

7. Hsieh T, Wu JM. Induction of apoptosis and altered nuclear/cytoplasmic distribution of the androgen receptor and prostate-specific antigen by 1alpha,25-dihydroxyvitamin D3 in androgen-responsive LNCaP cells. Biochem Biophys Res Commun. 1997;235(3):539-544.

8. Bao BY, Yeh SD, Lee YF. 1alpha,25-dihydroxyvitamin D3 inhibits prostate cancer cell invasion via modulation of selective proteases. Carcinogenesis. 2006;27(1):32-42.

9. Bao BY, Yao J, Lee YF. 1alpha, 25-dihydroxyvitamin D3 suppresses interleukin-8-mediated prostate cancer cell angiogenesis. Carcinogenesis. 2006;27(9):1883-1893.

10. Blutt SE, Allegretto EA, Pike JW, Weigel NL. 1,25-dihydroxyvitamin D3 and 9-cis-retinoic acid act synergistically to inhibit the growth of LNCaP prostate cells and cause accumulation of cells in G1. Endocrinology. 1997;138(4):1491-1497.

11. Jensen SS, Madsen MW, Lukas J, Binderup L, Bartek J. Inhibitory effects of 1alpha,25-dihydroxyvitamin $\mathrm{D}(3)$ on the $\mathrm{G}(1)-\mathrm{S}$ phase-controlling machinery. Mol Endocrinol. 2001;15(8):1370-1380.

12. Flores O, Wang Z, Knudsen KE, Burnstein KL. Nuclear targeting of cyclin-dependent kinase 2 reveals essential roles of cyclin-dependent kinase 2 localization and cyclin $\mathrm{E}$ in vitamin D-mediated growth inhibition. Endocrinology. 2010;151(3):896-908.
13. Blutt SE, McDonnell TJ, Polek TC, Weigel NL. Calcitriol-induced apoptosis in LNCaP cells is blocked by overexpression of Bcl-2. Endocrinology. 2000;141(1):10-17.

14. Koli K, Keski-Oja J. 1alpha,25-dihydroxyvitamin D3 and its analogues down-regulate cell invasion-associated proteases in cultured malignant cells. Cell Growth Differ. 2000;11(4):221-229.

15. van der Rhee HJ, de Vries E, Coebergh JW. Does sunlight prevent cancer? A systematic review. Eur J Cancer. 2006;42(14):2222-2232.

16. Tabayoyong W, Abouassaly R. Prostate cancer screening and the associated controversy. Surg Clin North Am. 2015;95(5):1023-1039.

17. Schwartz GG, Hulka BS. Is vitamin D deficiency a risk factor for prostate cancer? (Hypothesis). Anticancer Res. 1990;10(5A):1307-1311.

18. Blutt SE, Weigel NL. Vitamin D and prostate cancer. Proc Soc Exp Biol Med. 1999;221(2):89-98.

19. Huncharek M, Muscat J, Kupelnick B. Dairy products, dietary calcium and vitamin $\mathrm{D}$ intake as risk factors for prostate cancer: a meta-analysis of 26,769 cases from 45 observational studies. Nutr Cancer. 2008;60(4):421-441.

20. Whitlatch LW, Young MV, Schwartz GG, Flanagan JN, Burnstein KL, Lokeshwar BL, Rich ES, et al. 25-Hydroxyvitamin D-1alpha-hydroxylase activity is diminished in human prostate cancer cells and is enhanced by gene transfer. J Steroid Biochem Mol Biol. 2002;81(2):135140.

21. Xu Y, Shao X, Yao Y, Xu L, Chang L, Jiang Z, Lin Z. Positive association between circulating 25-hydroxyvitamin $\mathrm{D}$ levels and prostate cancer risk: new findings from an updated meta-analysis. J Cancer Res Clin Oncol. 2014;140(9):1465-1477.

22. Chandler PD, Giovannucci EL, Scott JB, Bennett GG, Ng $\mathrm{K}$, Chan AT, Hollis BW, et al. Null association between vitamin D and PSA levels among black men in a vitamin D supplementation trial. Cancer Epidemiol Biomarkers Prev. 2014;23(9):1944-1947. 